\title{
Multispecialty multidisciplinary input into comorbidities in heart failure reduces hospitalisation and clinic attendance
}

Short Title: Virtual Multispeciality Input for Heart Failure Comorbidities

Essa $\mathrm{H}^{1,2}$, Walker $\mathrm{L}^{1,2}$, Mohee $\mathrm{K}^{1}$, Oguguo $\mathrm{E}^{1}$, Douglas $\mathrm{H}^{1}$, Kahn, $\mathrm{M}^{2}$, Rao $\mathrm{A}^{2}$, Bellieu $\mathbf{J}^{1}$, Hadcroft $\mathbf{J}^{1}$, Hartshorne-Evans $\mathrm{N}^{4}$, Bliss $\mathrm{J}^{3}$, Akpan $\mathrm{A}^{1,2,5}$, Wong $\mathrm{C}^{1,2,5}$, Cuthbertson DJ ${ }^{1,5}$, Sankaranarayanan $\mathrm{R}^{1,2,4,5}$

${ }^{1}$ Liverpool University Hospitals NHS Foundation Trust,

${ }^{2}$ Liverpool Centre for Cardiovascular Science, University of Liverpool, Liverpool Heart \& Chest Hospital, Liverpool, UK

${ }^{3}$ Liverpool Clinical Commissioning Group

${ }^{4}$ The Pumping Marvellous Foundation

${ }^{5}$ University of Liverpool

\section{Author Contact information}

1. Dr Hani Essa MRCP

Cardiology Specialty Trainee and NIHR Academic Clinical Fellow

Aintree University Hospital, Liverpool University Hospitals NHS Foundation Trust

Lower Lane Liverpool L9 7AL

United Kingdom

Email hani_essa@hotmail.com

2. Dr Lauren Walker BSc (Hons) MBChB (Hons) MRCP (UK) PhD PGCAP FHEA NIHR Academic Clinical Lecturer in Clinical Pharmacology and Therapeutics, Consultant Clinical Pharmacologist

Liverpool University Hospitals NHS Foundation Trust and University of Liverpool

Liverpool L9 7AL UK

Email - Lauren.Walker@liverpool.ac.uk

3. Dr Kevin Mohee MBChB MRCP(UK)

Cardiology Clinical Fellow 
Aintree University Hospital

Liverpool University Hospitals NHS Foundation Trust

Liverpool L9 7AL UK

Email Kevin.Mohee@liverpoolft.nhs.uk

\section{Dr Emeka Oguguo}

Consultant Heart Failure Cardiologist and Deputy Clinical Director

Liverpool University Hospitals NHS Foundation Trust

Liverpool L9 7AL UK

EmailEmeka.Oguguo@liverpoolft.nhs.uk

5. Dr Homeyra Douglas MD, FRCP

Care Group Clinical Director (Cardiology \& Respiratory)

Consultant Cardiologist

Aintree University Hospital

Liverpool University Hospitals NHS Foundation Trust

Liverpool L9 7AL

Email - Homeyra.Douglas@liverpoolft.nhs.uk

6. Dr Matthew Kahn MbChB MRCP PhD

Consultant Cardiologist (Heart Failure and Devices)

Liverpool Heart and Chest Hospital

Thomas Drive, Liverpool

Matthew.Kahn@lhch.nhs.uk

7. Dr Archana Rao MBBS, FRCP, MD, FHEA

Consultant Cardiologist (Heart Failure and Devices)

Liverpool Heart and Chest Hospital

Thomas Drive, Liverpool

Archana.Rao@lhch.nhs.uk

8. Dr Julie Bellieu MB ChB FRCP

Specialty Clinical Lead for Palliative and End of Life Care,

Aintree University Hospital,

Liverpool University Hospitals NHS Foundation Trust

Liverpool L9 7AL UK

9. Dr Justine Hadcroft MB ChB FRCP

Consultant Respiratory Physician

Royal Liverpool and Broadgreen Hospital

Liverpool University Hospitals NHS Foundation Trust

Prescot St, Liverpool L7 8XP, UK

Email - Justine.Hadcroft @ liverpoolft.nhs.uk

10. Nick Hartshorne-Evans (Heart Failure Expert Patient Representative)

Chief Executive and Founder

The Pumping Marvellous Foundation (Heart Failure Charity) 
Suite 111 Business First Millenium City Park,

Millennium Road, Preston PR2 5BL

Email - nick@pumpingmarvellous.org

\title{
11. Dr Janet Bliss MBBS MRCGP
}

General Practitioner Partner

Grey Road Surgery

Clinical Vice-Chair

NHS Liverpool Clinical Commissioning Group

Email - Janet.Bliss@livgp.nhs.uk

\section{Professor Asan Akpan MPHIL MPH FRCP FAcadMed}

Visiting Professor (University of Cumbria),

Honorary Clinical Associate Professor (University of Liverpool)

Consultant Geriatrician, Liverpool University Hospitals NHS FT,

Ageing Specialty Research Group Lead (Clinical Research Network Northwest Coast)

and Chair of the Mersey British Geriatrics Society

Email Asan.Akpan@liverpoolft.nhs.uk

\section{Professor Christopher Wong MBBCh MRCP(I)}

Consultant Nephrologist \& General Physician

Visiting Professor in Health Sciences - Liverpool Hope University

Aintree University Hospital

Liverpool University Hospitals NHS Foundation Trust

Liverpool L9 7AL

Email - Christopher.Wong@liverpoolft.nhs.uk

\section{Professor Daniel J Cuthbertson BSc (Hons) PhD FRCP}

Reader and Honorary Consultant Physician in Diabetes and Endocrinology

Aintree University Hospital

Liverpool University Hospitals NHS Foundation Trust and University of Liverpool

Liverpool L9 7AL

Email - Dan.Cuthbertson@liverpool.ac.uk

15. Dr Rajiv Sankaranarayanan MBBS FRCP (Lon) FESC PhD (Corresponding Author) Heart Failure Clinical Lead Consultant Cardiologist, NIHR Research Scholar and Honorary Senior Clinical Lecturer University of Liverpool, Liverpool Centre for Cardiovascular Science

Liverpool University Hospitals NHS Foundation Trust

Email Rajiv.Sankaranarayanan@liverpoolft.nhs.uk

Fax 01515292724

\author{
Abbreviations \\ HF - Heart Failure \\ MDT - multidisciplinary team \\ IHD - Ischaemic Heart Disease \\ $\mathrm{AF}$ - atrial fibrillation \\ HTN - hypertension
}


CKD - chronic kidney disease

DM - diabetes mellitus

COPD - chronic obstructive pulmonary disease

\begin{abstract}
Aims

Heart failure (HF) is associated with multiple co-morbidities which independently influence response to treatment as well as outcomes. This retrospective observational study (January 2020-June 2021) analysed the impact of monthly virtual HF multi-specialty multidisciplinary team (MDT) meetings to address the management of associated comorbidities and thereby upon provision, cost of care and HF outcomes.
\end{abstract}

\title{
Methods
}

Patients acted as their own controls, with outcomes compared for equal periods (for each patient) pre versus post-MDT meeting. The MDT comprised of HF cardiologists (primary, secondary, tertiary care), HF specialist nurses (hospital, community), nephrologist, endocrinologist, palliative care specialist, chest physician, pharmacist, clinical pharmacologist and geriatrician. Outcome measures were 1) all-cause hospitalisations, 2) outpatient clinic attendances, and 3) cost.

\section{Results}

334 patients (mean age $72.5 \pm 11$ years) were discussed virtually through MDT meetings and follow-up duration was $13.9 \pm 4$ months. The mean age-adjusted Charlson Co-morbidity Index was 7.6 \pm 2.1 and Rockwood Frailty Score was $5.5 \pm 1.6$. The mean number of clinic attendances prevented was $1.6 \pm 0.4$. The total cost of funding monthly meetings for the duration of the study was $£ 32400$ and the 64 clinic appointments generated cost $£ 9600$. The MDT meetings prevented 534 clinic appointments (cost saving £80,100) and reduced allcause hospitalisations (pre-MDT meeting $1.1 \pm 0.4$ vs. $0.6 \pm 0.1$ post-MDT meeting; $\mathrm{p}<0.001$ ), reduction of 1586 hospital bed-days and cost-savings of $£ 634,400$. The total cost-saving to the healthcare system was $£ 672,500$.

\section{Conclusion}

The HF multispecialty virtual MDT model provides integration of care across all tiers of healthcare for HF management and a holistic approach addressing associated co-morbidities. 
This approach can reduce the need for out-patient attendances and all-cause hospitalisations, leading to significant cost-savings.

\section{Keywords}

heart failure; team-based care; comorbidities; outpatient clinics; hospitalisation

\section{Key questions}

\section{What is already known about this subject?}

Heart failure is associated with several co-morbid health conditions (multi-morbidity) which independently influence outcomes as well as response to treatment.

\section{What does this study add?}

This study assesses the impact of multispecialty multi-morbidity input into the management of co-morbidities and thereby the effect upon all-cause outcomes.

\section{How might this impact on clinical practice?}

Results of this study illustrate that multi-speciality management of comorbidities associated with heart failure, may not only improve all-cause outcomes but could also prove to be cost-beneficial. 


\section{Introduction}

Heart failure (HF) is a complex clinical syndrome, representing the final common pathway of many different pathological processes and associated with high mortality and frequent hospital admissions ${ }^{1}$. There are an estimated 60 million cases of HF worldwide ${ }^{2}$. This global burden is expected to increase with an aging population, with $80 \%$ of hospitalisations occurring in those aged $>65$ years $^{3}$. Significantly, hospitalisation confers a poor long term prognosis with a 5-year mortality of $75 \% 4$.

$\mathrm{HF}$ is frequently characterised by multi-morbidity with patients suffering from many other comorbid conditions (long-term conditions) that can influence the management and adversely affect outcomes. These include other cardiovascular diseases such as ischaemic heart disease (IHD), atrial fibrillation (AF) and hypertension and non-cardiovascular comorbidities such as chronic kidney disease (CKD) (41\%), anaemia (37\%), diabetes mellitus (type 1 or type 2) (DM-21\%), chronic obstructive pulmonary disease (COPD) (24\%), a burden of polypharmacy and frailty ${ }^{5,6}$. Most HF patients have at least one comorbidity ${ }^{6,7}$ with up to $40 \%$ of patients with $\mathrm{HF}$ with $\geq 5$ co-morbidities (this group contributed to $>80 \%$ of the overall in-hospital stay $)^{8}$. The number of comorbidities is higher amongst patients with heart failure with preserved ejection fraction $(\mathrm{HFpEF})$ than in patients with heart failure with reduced ejection fraction $(\mathrm{HFrEF})$ and with a more profound impact upon outcomes ${ }^{9-13}$. In addition, non-cardiac comorbidities independently affect response to treatment, influence disease severity and HF outcomes such as hospitalisation, quality of life and mortality ${ }^{7,12-19}$. The burden of comorbidities is also progressively increasing with time ${ }^{13,20}$.

This level of multi-morbidity and complexity can be most effectively managed by a multidisciplinary team (MDT), an approach endorsed by both the European Society of Cardiology (ESC) (Class 1A recommendation) ${ }^{21}$ and the American Heart Association (AHA)

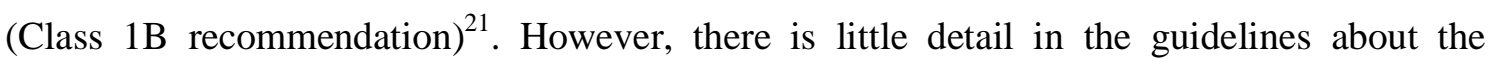
composition or remit of such an MDT. There is also a dearth of evidence currently regarding whether management of comorbidities by relevant specialists in consultation with $\mathrm{HF}$ specialists can improve HF outcomes.

The aim of this study is to assess the impact of multi-specialty input on the optimisation of comorbidities, all-cause hospitalisations, out-patient clinic attendances and mortality in patients with heart failure. 


\section{Methods}

Study settings and time period

This study complies with the Declaration of Helsinki and was approved as a service evaluation project by the Research Governance Committee (Institutional Review Board) at Liverpool University Hospitals NHS Foundation Trust and Liverpool Health Partners. It was conducted as an observational cohort study in a British University teaching hospital, looking at the impact of a multispecialty HF MDT meeting on care models and outcomes in a HF population. We studied outcomes of our patients with HF at monthly virtual multispecialty meetings from January 2020 to June 2021 and followed up for equal amounts of time pre and post recruitment. We followed the STROBE guidelines (The Strengthening the Reporting of Observational Studies in Epidemiology) for reporting observational studies ${ }^{22}$.

\section{MDT meeting format}

Since January 2020, the Liverpool Multi-specialty regional HF MDT meetings have been funded by Liverpool Single Services Cardio-respiratory Group (from Liverpool Clinical Commissioning Group) and Liverpool University Hospitals NHS Foundation Trust. The multi-specialty meeting is conducted monthly via video-conferencing. Sources of referral include community heart failure teams, hospital HF teams (secondary and tertiary care) and other specialty teams, using a dedicated referral form (Supplementary material). The multispecialty multidisciplinary team consist of HF cardiologists from the community, secondary care and tertiary care, heart failure specialist nurses from the community and hospital, nephrologist, endocrinologist, palliative care specialist, chest physician, geriatrician, pharmacist and pharmacologist. Individualised discussions at the multispecialty MDT meeting include optimisation of HF therapies, assessment of frailty, comorbidities, cardiorenal metabolic status, specialist input into any complex chronic respiratory pathologies, need for falls risk assessment, cognitive dysfunction, rationalisation of polypharmacy burden (particularly anti-cholinergic burden), medication compliance and need for advanced care planning discussions or community palliative care where appropriate. Recommendations are made as consensus from the multispecialty meeting. These are then conveyed electronically or through post to the referrers, the electronic record of each discussed patient is also updated with these recommendations and the MDT consensus discussed with each patient. 


\section{Demographic and clinical details}

We collected demographic data, medication history, co-morbidities such as diabetes mellitus, hypertension, ischaemic heart disease (IHD), chronic obstructive pulmonary disease (COPD) or a pre-existing malignant condition. Furthermore we computed the Charlson Comorbidity Index $(\mathrm{CCI})^{23}$ and the Rockwood clinical frailty score ${ }^{24}$. Patients were followed up for equal amounts of time pre and post MDT meeting, so "each patient acted as their own control".

\section{Outcome measures}

Outcome measures assessed were all-cause hospitalisations and outpatient clinic attendances for an equal period of time pre and post MDT meeting. We also assessed other measures such as advanced HF management (device therapy, transplant referrals), referrals to integrated palliative care services, burden of polypharmacy and all-cause mortality.

\section{Statistical analysis}

For the descriptive statistics of our patient population, we represented continuous variables as means with standard deviations or medians with interquartile ranges in the case of non-parametric data. Categorical variables were represented with percentages and analysed using Chi-squared test. Statistical comparisons were made for parametric data using Student's $\mathrm{T}$ test and for nonparametric data using Mann-Whitney test. Statistical analysis was carried out using the Statistical Package for the Social Sciences (SPSS 23.0, IBM Corp., Armonk, New York, USA).

\section{Results}

\section{Demographic details}

334 patients were discussed through virtual MDT meetings from January 2020 to June 2021. We collated baseline patient characteristics as illustrated in Table 1. This service model continued uninterrupted during the COVID-19 pandemic. The mean age of patients discussed was $72.5 \pm 11$ years and follow-up duration was $13.9 \pm 4$ months. $43 \%$ of the patients discussed were female and $45 \%$ of patients had a diagnosis of $\mathrm{HFpEF}$.

The mean age-adjusted Charlson Co-morbidity Index was $7.6 \pm 2.1$ and Rockwood Frailty Score was $5.5 \pm 1.6$. There was significant polypharmacy burden as indicated by the mean number of medications of $12.1 \pm 3.9$ amongst the whole cohort. 


\section{Clinical recommendations}

Consensus recommendation was made from the MDT regarding medication optimisation such as addition of sodium glucose-like co-transporter-1 (SGLT2inhibitor) in patients with $\mathrm{HF}$, diabetes or CKD. Appropriate de-prescribing of polypharmacy was also performed to reduce the anticholinergic burden (mean number of medications reduced $-1.4 \pm 1$ ) and $9 \%$ of patients were referred to the falls assessment clinic. (53/334 (16\%) patients underwent internal cardiovertor-defibrillator (ICD) or cardiac resynchronisation therapy (CRT) pacemaker implant as a result of consensus recommendations from the multispecialty MDT and 11/334 (3\%) patients were referred for transplant assessment. (16/334) 5\% of patients were referred to dialysis assessment clinics and 10 patients were instituted on dialysis.

$37 / 334(11 \%)$ patients required community palliative care, 9 of these patients required admission to a hospice and 11 patients required deactivation of their ICD as a part of advanced care planning palliative care. Overall mortality of this cohort during follow-up was $21 \%(70 / 334)$.

\section{Hospitalisations}

As shown in figure 1, the number of all-cause hospitalisations was reduced significantly (pre-MDT $1.1 \pm 0.4$ vs.0.6 \pm 0.1 post MDT; $\mathrm{p}<0.001$ ), leading to a saving of 1586 bed-days and estimated cost-saving $£ 634,400$ (average cost per bed day $£ 400^{25}$ ).

\section{Out-patient attendances}

The number of outpatient clinic attendances prevented 534. This reduced inconvenience to patients and also potentially saved patients money. This includes avoidance of need for travel as well as waiting time in clinic (average 51.3 minutes ${ }^{26}$, transport and parking costs (average saving of $£ 5.52$ per patient per appointment by car and $£ 4.60$ by bus) ${ }^{27}$. There was also the added positive environmental impact through carbon footprint reduction (in this study $554 \mathrm{kgCO} 2)$. 


\section{Economic analysis}

We also performed an economic analysis of the impact of the virtual multispecialty MDT. This is also illustrated in Table 2. The total cost of funding the multispecialty MDT meeting was 0.5 programmed activity (PA) NHS rates ${ }^{28}$ per speciality ( $£ 1800$ per meeting and $£ 32400$ for the duration of the study (Jan 2020 - Jun 2021). 64 clinic appointments they generated cost an estimated $£ 9600$ ( $£ 150$ per outpatient clinic $^{25}$ ). However, the MDT meetings also prevented 534 clinic appointments (cost saving £80,100). As shown in Table 2, the total saving to the healthcare system was $£ 672,500$.

\section{Discussion}

Several previous studies have shown the co-existence and adverse impact of multimorbidity in patients with HF. However, this is the first study to demonstrate that multispecialty, multidisciplinary management of comorbidities with integration of community, secondary and tertiary care HF specialists, is associated with reduced all-cause hospitalisations and outpatient clinic attendances. The MDT also optimised the care of multiple comorbidities and facilitated timely involvement of relevant specialties.

It is important to focus on the management of multi-morbidity along with the management of HF itself. Other studies have demonstrated that HF contributes to a smaller proportion of the burden of hospitalisation (less than 20\%), non-cardiovascular causes contribute to more than $60 \%$ of the burden of hospitalisations ${ }^{5,29}$. Small studies (randomised and observational) have shown that treatment of individual comorbidities such as sleep apnoea $^{30}$, anaemia ${ }^{31}, \mathrm{AF}^{32}$ and obesity ${ }^{33}$, can reduce hospitalisation and mortality in $\mathrm{HF}$ patients. A focus on management of comorbidities is relevant for all types of HF, but particularly for $\mathrm{HFpEF}^{34}$ in which no treatment has been uniformly demonstrated to have prognostic benefit. Previous data from our centre has also demonstrated that in $48 \%$ of $\mathrm{HF}$ patents reviewed in a joint cardio-renal MDT meeting reduced the need for further cardiology or renal outpatient follow-up ${ }^{35}$. However, there is significant variation and disparity in the management of heart failure and associated co-morbidities depending on the geographical location of the patient and health care professional ${ }^{36}$. Specialists frequently focus on a single disease entity, potentially with a deleterious effect on other organ/ systems (one such example is the occurrence of worsening renal function in patients with HFrEF during decompensated $\mathrm{HF}$, prompting cessation of renin-angiotensin aldosterone inhibitors and in turn leading to worsening HF outcomes). 
Disease management programs incorporating MDT input from dietician, social worker, physical therapist, and pharmacist have shown a significant reduction in thirty-day readmissions rates $^{37}$, however we note the variable definition of the constitution of a MDT and variable effects of MDT input into HF outcomes ${ }^{38}$. Members of the MDT have included HF specialist nurses, HF consultants, pharmacists, dieticians, social care workers, physiotherapists, palliative care specialists and psychologists. The largest study of MDT intervention (COACH Study) showed neutral outcomes in terms of HF hospitalisations or mortality $^{39}$. It is possible that the lack of specialist input into intensive management of comorbidities may have diluted the effects of MDT input. The strategy of incorporation of other specialists (nephrologist, diabetologist, geriatrician, chest physician, pharmacologist, palliative care) to address comorbidities simultaneously along with HF specialists, is novel and timely, particularly considering the cardiac, renal and metabolic impact of heart failure therapies such as the SGLT2 inhibitors.

Our service model (Figure 2) exemplifies individualised, patient-centric, holistic care using a consensus approach targeted to the management of HF and comorbidities jointly. The need to address and manage co-morbidities frequently prompts referral to other specialty outpatient clinics. Repeated out-patient clinic attendances are inconvenient to otherwise frail and often less mobile patients. We have demonstrated that a virtual multispecialty MDT is associated with time, travel and cost savings and a significant reduction in inter-specialty referrals/ outpatient clinic attendances.

Virtual MDT clinics have been particularly relevant during the COVID-19 pandemic when this particularly vulnerable cohort prefer to avoid travel and minimise the risk of hospital-acquired infection (findings supported by our national HF patient survey regarding the impact of the COVID-19 pandemic upon HF services $)^{40}$. Our virtual multispecialty MDT model importantly ensured that the management of patients with HF continued uninterrupted throughout the COVID-19 pandemic, whilst minimising the need for patients to attend face to face outpatient clinic appointments.

We acknowledge limitations to this study including the observational nature; the efficacy of this service model maybe be best evaluated through a randomised controlled trial. Limitations of the virtual MDT approach also include the potential for miscommunication in view of lack of patient presence during the meeting. This was minimised by spoken and 
written discussions with the patient prior to and subsequent to the meeting. The model requires robust service planning to ensure attendance of multiple specialists and members of the multidisciplinary team.

In conclusion, we demonstrate that an integrated and virtual multidisciplinary input is associated with improved heart failure outcomes through a reduction in all-cause hospitalisations and clinic attendances and is not only patient-centred but also cost-effective. Application of this model could be considered the gold standard approach in addressing multi-morbidity in patients with heart failure.

\section{Acknowledgements - none}

Sources of funding - The MDT meetings are funded by the Liverpool Single Services Cardio-Respiratory Operation Group, Liverpool Clinical Commissioning Group and Liverpool University Hospitals NHS Foundation Trust

Declaration of Interest: none declared

Data Availability Statement - The data underlying this article will be shared on reasonable request to the corresponding author 


\author{
Reference List
}

(1) Rathi S, Deedwania PC. The epidemiology and pathophysiology of heart failure. Med Clin North Am 2012 September;96(5):881-90.

(2) Stewart S, MacIntyre K, Capewell S, McMurray JJ. Heart failure and the aging population: an increasing burden in the 21st century? Heart 2003 January;89(1):49-53.

(3) Laribi S, Aouba A, Nikolaou M et al. Trends in death attributed to heart failure over the past two decades in Europe. Eur J Heart Fail 2012 March;14(3):234-9.

(4) Maclntyre K, Capewell S, Stewart S et al. Evidence of improving prognosis in heart failure: trends in case fatality in 66547 patients hospitalized between 1986 and 1995. Circulation 2000 September 5;102(10):1126-31.

(5) Dunlay SM, Redfield MM, Weston SA et al. Hospitalizations after heart failure diagnosis a community perspective. J Am Coll Cardiol 2009 October 27;54(18):1695-702.

(6) van Deursen VM, Urso R, Laroche $C$ et al. Co-morbidities in patients with heart failure: an analysis of the European Heart Failure Pilot Survey. Eur J Heart Fail 2014 January;16(1):10311.

(7) Gimeno-Miguel A, Gracia GA, Poblador-Plou B et al. Multimorbidity patterns in patients with heart failure: an observational Spanish study based on electronic health records. BMJ Open 2019 December 23;9(12):e033174.

(8) Braunstein JB, Anderson GF, Gerstenblith G et al. Noncardiac comorbidity increases preventable hospitalizations and mortality among Medicare beneficiaries with chronic heart failure. J Am Coll Cardiol 2003 October 1;42(7):1226-33.

(9) Chamberlain AM, St Sauver JL, Gerber $Y$ et al. Multimorbidity in heart failure: a community perspective. Am J Med 2015 January;128(1):38-45.

(10) Pfeffer MA, Swedberg K, Granger CB et al. Effects of candesartan on mortality and morbidity in patients with chronic heart failure: the CHARM-Overall programme. Lancet 2003 September 6;362(9386):759-66.

(11) Dunlay SM, Roger VL, Redfield MM. Epidemiology of heart failure with preserved ejection fraction. Nat Rev Cardiol 2017 October;14(10):591-602.

(12) Bhatt AS, Ambrosy AP, Dunning A et al. The burden of non-cardiac comorbidities and association with clinical outcomes in an acute heart failure trial - insights from ASCEND-HF. Eur J Heart Fail 2020 June;22(6):1022-31.

(13) Pandey A, Vaduganathan M, Arora S et al. Temporal Trends in Prevalence and Prognostic Implications of Comorbidities Among Patients With Acute Decompensated Heart Failure: The ARIC Study Community Surveillance. Circulation 2020 July 21;142(3):230-43. 
medRxiv preprint doi: https://doi.org/10.1101/2022.01.31.22270113; this version posted February 1, 2022. The copyright holder for this preprint (which was not certified by peer review) is the author/funder, who has granted medRxiv a license to display the preprint in perpetuity.

It is made available under a CC-BY-ND 4.0 International license .

(14) Cubbon RM, Gale CP, Kearney LC et al. Changing characteristics and mode of death associated with chronic heart failure caused by left ventricular systolic dysfunction: a study across therapeutic eras. Circ Heart Fail 2011 July;4(4):396-403.

(15) Horiuchi $Y$, Tanimoto $S$, Latif AHMM et al. Identifying novel phenotypes of acute heart failure using cluster analysis of clinical variables. Int J Cardiol 2018 July 1;262:57-63.

(16) Manemann SM, Chamberlain AM, Roger VL et al. Multimorbidity and Functional Limitation in Individuals with Heart Failure: A Prospective Community Study. J Am Geriatr Soc 2018 July;66(6):1101-7.

(17) Joyce E, Chung C, Badloe S et al. Variable Contribution of Heart Failure to Quality of Life in Ambulatory Heart Failure With Reduced, Better, or Preserved Ejection Fraction. JACC Heart Fail 2016 March;4(3):184-93.

(18) Lawson CA, Solis-Trapala I, Dahlstrom U et al. Comorbidity health pathways in heart failure patients: A sequences-of-regressions analysis using cross-sectional data from 10,575 patients in the Swedish Heart Failure Registry. PLoS Med 2018 March;15(3):e1002540.

(19) Manemann SM, Chamberlain AM, Boyd CM et al. Multimorbidity in Heart Failure: Effect on Outcomes. J Am Geriatr Soc 2016 July;64(7):1469-74.

(20) Conrad N, Judge A, Tran J et al. Temporal trends and patterns in heart failure incidence: a population-based study of 4 million individuals. Lancet 2018 February 10;391(10120):572-80.

(21) Ponikowski P, Voors AA, Anker SD et al. 2016 ESC Guidelines for the diagnosis and treatment of acute and chronic heart failure: The Task Force for the diagnosis and treatment of acute and chronic heart failure of the European Society of Cardiology (ESC). Developed with the special contribution of the Heart Failure Association (HFA) of the ESC. Eur J Heart Fail 2016 August;18(8):891-975.

(22) von Elm E, Altman DG, Egger M, Pocock SJ, Gotzsche PC, Vandenbroucke JP. The Strengthening the Reporting of Observational Studies in Epidemiology (STROBE) Statement: guidelines for reporting observational studies. BMJ. 2007;335(7624):806-808.

(23) Charlson ME, Pompei P, Ales KL, Mackenzie CR. A new method of classifying prognostic comorbidity in longitudinal studies: development and validation. J Chronic Dis 1987;40(5):373-83.

(24) Rockwood K, Song $X$, Macknight $C$ et al. A global clinical measure of fitness and frailty in elderly people. CMAJ 2005 August 30;173(5):489-95.

(25) NHS England and NHS Improvement. National Cost Collection 2019. 1-1-2020.

Ref Type: Online Source

(26) Care Quality Commission. National summary of the Outpatients department 2011 survey. 29-5-2017.

Ref Type: Online Source

(27) de Lacy J. The Potential Economic Impact of Virtual Outpatient Appointments in the West Midlands: A scoping study. 13-8-2018.

Ref Type: Online Source 
medRxiv preprint doi: https://doi.org/10.1101/2022.01.31.22270113; this version posted February 1, 2022. The copyright holder for this preprint (which was not certified by peer review) is the author/funder, who has granted medRxiv a license to display the preprint in perpetuity.

It is made available under a CC-BY-ND 4.0 International license .

(28) NHS Employers, British Medical Association. A guide to consultant job planning. 12-4-2017. Ref Type: Online Source

(29) Madelaire C, Gustafsson F, Kristensen SL et al. Burden and Causes of Hospital Admissions in Heart Failure During the Last Year of Life. JACC Heart Fail 2019 July;7(7):561-70.

(30) O'Connor CM, Whellan DJ, Fiuzat M et al. Cardiovascular Outcomes With Minute VentilationTargeted Adaptive Servo-Ventilation Therapy in Heart Failure: The CAT-HF Trial. I Am Coll Cardiol 2017 March 28;69(12):1577-87.

(31) Lewis GD, Malhotra R, Hernandez AF et al. Effect of Oral Iron Repletion on Exercise Capacity in Patients With Heart Failure With Reduced Ejection Fraction and Iron Deficiency: The IRONOUT HF Randomized Clinical Trial. JAMA 2017 May 16;317(19):1958-66.

(32) Turagam MK, Garg J, Whang W et al. Catheter Ablation of Atrial Fibrillation in Patients With Heart Failure: A Meta-analysis of Randomized Controlled Trials. Ann Intern Med 2019 January 1;170(1):41-50.

(33) Sundstrom J, Bruze G, Ottosson J, Marcus C, Naslund I, Neovius M. Weight Loss and Heart Failure: A Nationwide Study of Gastric Bypass Surgery Versus Intensive Lifestyle Treatment. Circulation 2017 April 25;135(17):1577-85.

(34) Juilliere Y, Venner C, Filippetti L, Popovic B, Huttin O, Selton-Suty C. Heart failure with preserved ejection fraction: A systemic disease linked to multiple comorbidities, targeting new therapeutic options. Arch Cardiovasc Dis 2018 December;111(12):766-81.

(35) Sankaranarayanan R, Douglas H, Wong C. Cardio-nephrology MDT meetings play an important role in the management of cardiorenal syndrome. Br.J.Cardiol [27], 80-82. 2020.

Ref Type: Journal (Full)

(36) Gonzalez-Juanatey JR, Alegria EE, Bertomeu M, V, Conthe GP, de Santiago NA, Zsolt F, I. [Heart failure in outpatients: comorbidities and management by different specialists. The EPISERVE Study]. Rev Esp Cardiol 2008 June;61(6):611-9.

(37) Charais C, Bowers M, Do OO, Smallheer B. Implementation of a Disease Management Program in Adult Patients With Heart Failure. Prof Case Manag 2020 November;25(6):31223.

(38) Morton G, Masters J, Cowburn PJ. Multidisciplinary team approach to heart failure management. Heart 2018 August;104(16):1376-82.

(39) Jaarsma T, van der Wal MH, Lesman-Leegte I et al. Effect of moderate or intensive disease management program on outcome in patients with heart failure: Coordinating Study Evaluating Outcomes of Advising and Counseling in Heart Failure (COACH). Arch Intern Med 2008 February 11;168(3):316-24.

(40) Sankaranarayanan R, Hartshorne-Evans N, Redmond-Lyon S et al. The impact of COVID-19 on the management of heart failure: a United Kingdom patient questionnaire study. ESC Heart Fail 2021 April;8(2):1324-32. 
Table 1. Patient Characteristics

\begin{tabular}{|l|l|}
\hline Patient Characteristics & $\mathbf{N}=\mathbf{3 3 4}$ \\
\hline Age & $72.5 \pm 11$ years \\
\hline Male : Female & $57 \%: 43 \%$ \\
\hline HFrEF / HFmrEF & $55 \%$ \\
\hline HFpEF & $45 \%$ \\
\hline Ischaemic Heart Disease & $37 \%$ \\
\hline Hypertension & $49 \%$ \\
\hline Diabetes Mellitus & $41 \%$ \\
\hline Atrial Fibrillation & $38 \%$ \\
\hline Valvular Heart Disease & $18 \%$ \\
\hline COPD / Interstitial Lung Disease & $31 \%$ \\
\hline CKD & $53 \%$ \\
\hline Cerebrovascular disease (CVA or previous TIA) & $13 \%$ \\
\hline Cancer & $7.6 \pm 2.1$ \\
\hline Dementia & $5.5 \pm 1.6$ \\
\hline Charlson Comorbidity Index & \\
\hline Rockwood Frailty Score & \\
\hline & \\
\hline
\end{tabular}


Table 2 Economic analysis- healthcare savings

\begin{tabular}{|c|c|c|}
\hline & Expenditure & Saving \\
\hline Funding of specialties for MDT input & $£ 32400$ & \\
\hline Reduction in hospitalisations post MDT & & $\begin{array}{l}1.1 \text { pre MDT to } 0.6 \text { post }(3490-1904= \\
\text { saving of } 1586 \text { bed-days }=£ 634,400)\end{array}$ \\
\hline \multirow[t]{2}{*}{ Outpatient clinic visits post MDT } & $\begin{array}{l}64 \text { generated } \\
=£ 9600\end{array}$ & $\begin{array}{l}534 \text { clinic appointments prevented (cost } \\
\text { saving } £ 80,100)\end{array}$ \\
\hline & $\begin{array}{l}\text { Total } \\
\text { expenditure } \\
£ 42000\end{array}$ & $\begin{array}{l}\text { Total saving } \\
£ 714,500\end{array}$ \\
\hline $\begin{array}{l}\text { Total saving to the healthcare system = } \\
£ 672,500\end{array}$ & & \\
\hline
\end{tabular}


medRxiv preprint doi: https://doi.org/10.1101/2022.01.31.22270113; this version posted February 1, 2022. The copyright holder for this preprint (which was not certified by peer review) is the author/funder, who has granted medRxiv a license to display the preprint in perpetuity. It is made available under a CC-BY-ND 4.0 International license.

\section{Figure Legends}

Figure 1. Comparison of all-cause hospitalisations pre and post-multispeciality MDT meeting

Figure 2. Integrated Multispecialty MDT Model illustrating the team members involved in the MDT meetings 


\section{Fig.1}

\section{$\mathrm{p}<0.001$}

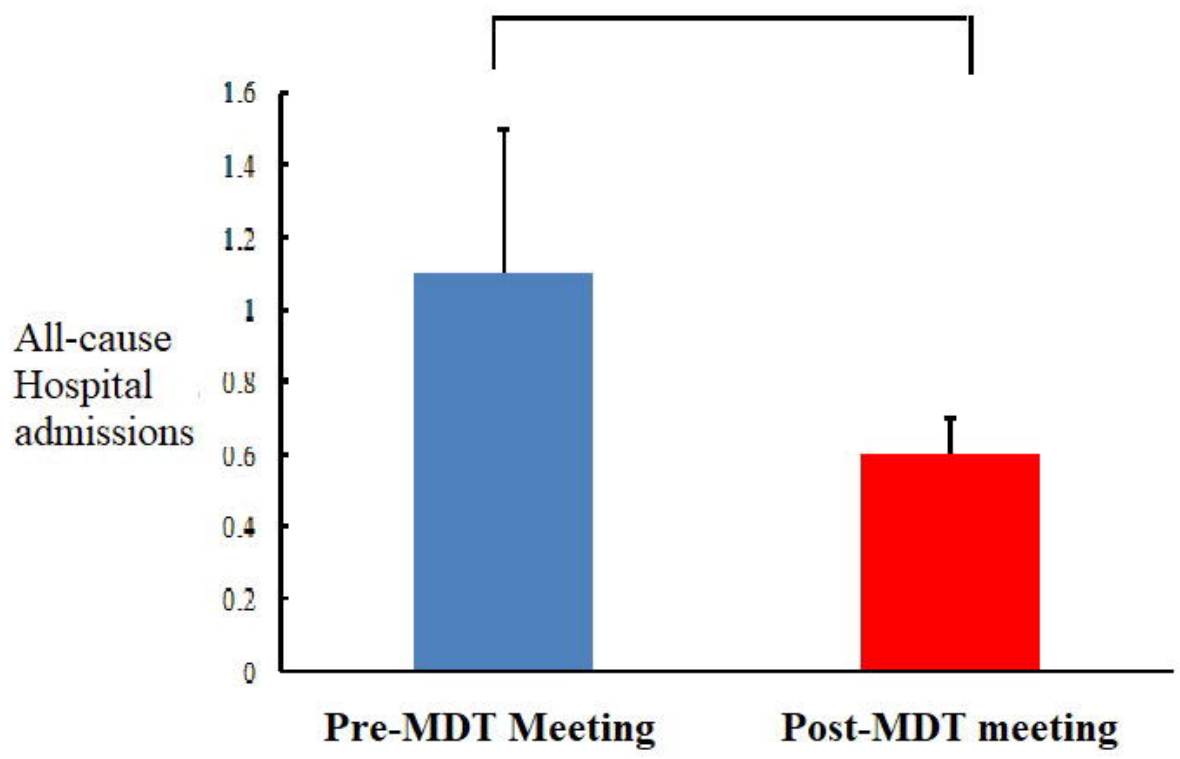


Fig.2 Integrated Multispecialty HF Model

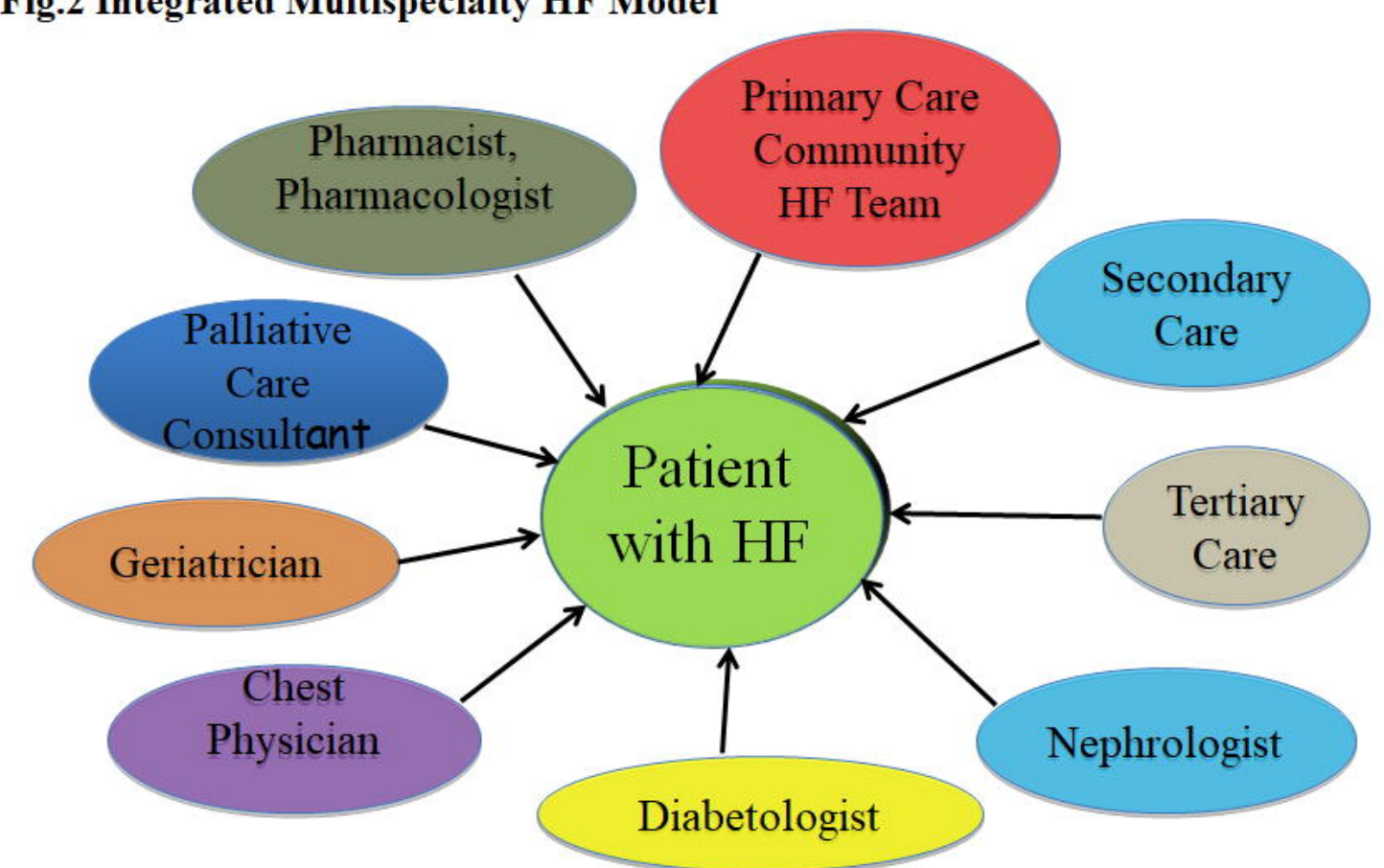

